\title{
Developing a New Teaching Approach for the Chemical Bonding Concept Aligned With Current Scientific and Pedagogical Knowledge
}

\author{
TAMI LEVY NAHUM, RACHEL MAMLOK-NAAMAN, AVI HOFSTEIN \\ Department of Science Teaching, The Weizmann Institute of Science, \\ Rehovot 76100, Israel \\ JOSEPH KRAJCIK \\ School of Education, The University of Michigan, Ann Arbor, MI 48109, USA
}

Received 16 July 2006; revised 11 December 2006, 22 December 2006; accepted 22 December 2006

DOI 10.1002/sce.20201

Published online 30 January 2007 in Wiley InterScience (www.interscience.wiley.com).

\begin{abstract}
The traditional pedagogical approach for teaching chemical bonding is often overly simplistic and not aligned with the most up-to-date scientific models. As a result, high-school students around the world lack fundamental understanding of chemical bonding. In order to improve students' understanding of this concept, it was essential to propose a systemic treatment, namely, revising the scientific content, the pedagogical approach, and the assessment methods regarding this concept. Therefore, the main goal of this study was to build a conceptual framework that provides an advanced scientific and pedagogical foundation regarding the chemical bonding concept—one that will guide chemistry curriculum developers as well. A conceptual framework for a new teaching approach was constructed with lead-chemistry teachers, science (chemistry) educators, and research chemists. We suggest that chemical bonding should be taught based on elemental principles and by using the idea of a continuum of bond strengths. Our process includes the formulation of learning goals aligned with current scientific knowledge. Moreover, we suggest that constructing assessment tasks on carefully specified learning goals, which are described in terms of learning performances, may enable educators to foster and examine much deeper levels of students' understanding. () 2007 Wiley Periodicals, Inc. Sci Ed 91:579-603, 2007
\end{abstract}

Correspondence to: Tami Levy Nahum; e-mail: ntami@weizmann.ac.il

Joseph Krajcik collaborated on this work while on sabbatical at the Department of Science Teaching, The Weizmann Institute of Science as the Weston visiting professor. 


\section{INTRODUCTION: A PROBLEMATIC CONCEPT AREA}

One of the goals of the chemistry-teaching community is to develop more effective and scientifically aligned strategies to teach high-school students the key concept of chemical bonding. According to Teichert and Stacy (2002), this attempt is motivated by many studies conducted worldwide that revealed that the traditional approach of teaching bonding is problematic. More specifically, during the last two decades, researchers have found that students lack a deep conceptual understanding of the key concepts regarding the bonding concept and fail to integrate their mental models into a coherent conceptual framework (Bodner \& Domin, 1998; Griffiths \& Preston 1992; Herron, 1996; Peterson \& Treagust, 1989; Taber 2001).

Bonding is a central concept in the chemistry teaching, and therefore a thorough understanding of it is essential for understanding almost every other topic in chemistry such as carbon compounds, proteins, polymers, acids and bases, chemical energy, and thermodynamics (Fensham, 1975; Gillespie, 1997; Hurst, 2002). According to the literature, bonding is considered by teachers, students, and chemists to be a very complicated concept (Gabel, 1996; Robinson, 2003; Taber, 1998, 2001; Tsaparlis, 1997). The concepts associated with chemical bonding and structure, such as covalent bonds, molecules, ions, giant lattices, and hydrogen bonds are abstract and in order to understand these concepts, students must be familiar with mathematical and physical concepts that are associated with the bonding concept such as orbitals, electronegativity, and polarity.

Students' misconceptions regarding this concept have been noted worldwide since students live and operate within the macroscopic world of matter and do not easily follow shifts between the macroscopic and submicroscopic levels (Gabel, 1996; Harrison \& Treagust, 2000; Johnstone, 1991; Robinson, 2003). Consequently, they tend to build themselves alternative conceptions and nonscientific mental models (Ben-Zvi, Eylon, \& Silberstein, 1986; Taber \& Coll, 2002). According to Taber (2002), most alternative conceptions in chemistry are not derived from the learner's informal experiences of the world but from prior science teaching. If so, we need to ask ourselves how often can teaching strategies and pedagogy mislead students? Students' alternative conceptions, which are considered to largely stem from the way they have been taught, have been labeled as pedagogical learning impediments (Taber, 2001).

This study is based on our previous work (Levy Nahum, Hofstein, Mamlok-Naaman, \& Bar-Dov, 2004) that we conducted during the academic years 2002-2004. We examined students' achievement in chemistry based on a high-stakes examination, the Israeli Matriculation Examination (ME) across 14 years. The questions entitled "chemical bonding and structure" that are provided each year are very similar. These questions and the students' answers were analyzed. Fourteen years of analyses revealed that students possess a variety of misconceptions regarding the chemical bonding concept. Although there has been a serious effort to overcome this problem, the same crucial misunderstanding regarding the bonding concept has arisen each year for the last two decades. We used several methods and sources in order to explore the problem. Based on the findings, we suggest that students demonstrate a superficial understanding of chemical bonding not only because this concept has intrinsic complexities but also as a result of external misleading factors concerning the traditional approach used for teaching the bonding concept. These factors are detailed in the sections that follow and supported by studies conducted worldwide. In view of that, we recommend making a radical change in the traditional approach used for teaching this concept.

The main goal of the current study is to develop a new teaching approach for the bonding concept by abandoning the traditional approach and construction of a reformed approach 
aligned with the scientists' views. We seek a more scientific and effective teaching approach in order to improve students' understanding of this concept. In this paper, we (a) review the problematic components of the traditional teaching regarding the concept of bonding, (b) describe the model we used for aligning the teaching of this concept with views of current science and pedagogical knowledge, (c) present our research study, (d) present the outcomes of this process: the formulation of learning goals, learning performances, and new assessment tasks, and (e) present the results of the analysis of an achievement test. Finally, in the discussion, we refer to the contribution of this process to the building of a new teaching approach and present our assumptions as to why we believe it may solve part of the problem.

\section{THEORETICAL BACKGROUND}

\section{The Traditional Approach for Teaching the Bonding Concept: A Universal Problem}

In order to rationalize the need to change the approach used to teach the bonding concept, we present for the reader the reasons for the dissatisfaction among the chemistry-teaching community regarding the current teaching and learning of this concept. We will refer to two main components based on our previous study and on the literature: (1) the traditional pedagogical approach, as it appears mainly in chemistry textbooks worldwide and (2) the assessment methods used in Israel (the requirements of the Matriculation Examination) with respect to its influence on teachers' instruction and students' learning regarding the bonding concept.

The Traditional Pedagogical Approach for Teaching the Bonding Concept: Several Problematic Aspects. The problematic approach in which this concept is presented in many chemistry textbooks worldwide has been examined extensively in the last two decades by researchers of chemistry teaching (Ashkenazi \& Kosloff, 2006; Atzmon, 1991; Hurst, 2002; Justi \& Gilbert, 2002; Taber, 1998). The traditional pedagogical approach used for studying bonding can be found not only in high-school textbooks but also in general chemistry textbooks intended for college freshmen.

In many chemistry textbooks, elements are conveniently classified as metals or nonmetals; sometimes a few semimetals are mentioned. Very often, this dichotomy among elements leads to a dichotomous classification of bonding related to compounds: covalent being between nonmetallic elements and ionic being between a metal and a nonmetal. The teaching of this concept is often too simplistic. According to Hurst (2002), the common approach used by curriculum developers is to present four different groups of substances: the ionic lattice, the molecular lattice, the covalent lattice, and the metallic lattice and to elaborate on and discuss each of these structures, regarding the type or types of chemical bonding between the particles. These chemical bond types (ionic, covalent, and metallic bonds) are often discussed as very different entities, and the polarity concept is introduced only as a property associated with covalent bonds.

Furthermore, many chemistry textbooks do not relate to hydrogen bonds and to van der Waals interactions as chemical bonds; according to Taber (1998), they are often presented as "just forces." Henderleiter, Smart, Anderson, and Elian (2001) suggest that hydrogen bonding is a basic chemical principle that has applications in all areas of chemistry. Acquiring an understanding of a complex concept, such as hydrogen bonding, and being able to apply that concept to a variety of situations is not a trivial task. Chemistry students need to be able to analyze situations in which hydrogen bonding can occur in 
order to understand many physical properties and molecular interactions. Introductory general chemistry textbooks define the hydrogen bond in different ways. Some definitions appear very clear-cut; others are convoluted and may mislead students. Variations among texts make it difficult for students and may hinder students' ability to apply their knowledge.

The traditional teaching of the bonding concept often provides students with several nonscientific conceptual frameworks such as the "octet rule" and the dichotomous way of classifying chemical bonds (Hurst, 2002; Taber \& Watts, 2000). For example, one way that textbooks simplify the chemical concept is by using anthropomorphic explanations; in his research, Taber (1998) showed that 10th-grade students often adopt as an explanatory principle the notion that atoms "want" to have "octets" or "full outer shells," and that chemical reactions often occur in order to allow atoms to achieve this "goal." Moreover, some high-school textbooks incorrectly refer to eight electrons in the third or higher shells as a full shell. Taber and Coll (2002) suggest not learning by the "octet framework," which may lead to learning impediments. The existence of bonding, which does not lead to atoms having full electron shells, is consequently something of a mystery to many students. Moreover, students may have difficulty accepting anything that is not clearly explicable in "octet" terms, such as a hydrogen bond as being a chemical bond. Hurst (2002) also refers to the "octet rule" as an oversimplification of the electronic structure of molecules. According to Taber (2005), oversimplifications have the potential to act as significant impediments to future learning.

The traditional pedagogical approach, as it appears in many textbooks, leads to overgeneralizations as well as a lack of scientific tools that may promote students' understanding. In sum, according to Wiggins and McTighe (1998), all teaching must simplify, but there is a fundamental difference between developmentally simplified instruction and an overly simplistic approach that hides the uncertainties, arguments, and never revisits the simplistic models. Such textbooks (and the teaching they foster) imply that thought, creativity, skepticism, or argumentation are no longer needed. The consequence of such a presentation is reducing students' questioning, which is essential for a deeper understanding of the big ideas. Kesidou and Roseman (2002) claim that curriculum materials have a major role in teaching and learning, and many teachers rely on them to provide some of their content and their pedagogical content knowledge. In acknowledging the role of curriculum materials in teaching and learning, both science education researchers and policy makers have called for systematic, research-based reviews of science curriculum materials as a means of improving their quality, influencing teacher practice, and supporting science-teaching reform.

The Traditional Methods of Assessing Students' Knowledge of the Bonding Concept: Several Problematic Aspects. According to Wilson and Bertenthal (2006), the success of an assessment system depends on the nature and quality of the items, the strategies and the tasks that are used to gather evidence of student learning, as well as the methods used to interpret the meaning of students' performance in using those measures.

The findings from our diagnostic research study that we have mentioned previously (Levy Nahum et al., 2004), led us to assume that the current method of evaluating students has a critical impact on the teaching and learning of the bonding concept, i.e., the teachers' main objective is to prepare their students for the examination and this is done by providing them with absolute definitions and a set of rigid rules, which inevitably leads to superficial teaching and meaningless learning. The analysis suggests that the general approach of the curriculum along with the current system of assessment cause students to memorize key 
phrases and explain facts by using declarative knowledge, resulting in students lacking a fundamental understanding of this concept.

The ME-type questions (the common questions) and the corresponding "acceptable answers" are problematic due to the following factors: (a) they are not always aligned with the views of chemists and (b) they are often based on memorization and thus do not foster students' understanding. Two examples of common questions and the answers that are acceptable to the Ministry of Education are as follows:

(a) A question and the corresponding answer, which are not aligned with currently studied science:

\begin{abstract}
Which material has a higher melting point $-\mathrm{BaCl}_{2}$ or $\mathrm{C}$ (diamond)? Justify your answer.

The acceptable answer for this question: The melting point of $\mathrm{C}$ (diamond) is higher than the melting point of $\mathrm{BaCl}_{2}$ because the covalent bonds between the carbon atoms in the diamond are stronger than the ionic bonds in $\mathrm{BaCl}_{2}$.
\end{abstract}

For many years, chemists in Israel argue that this type of question is not relevant to ask since the students are required to compare the melting point of two different structures of giant lattices, and students cannot use qualitative understanding in order to answer it (R. Naaman, personal communication, November 14, 2002). Thus, their answer to such questions can be based only on memorization of nonscientific overgeneralizations with no understanding of bond strength.

(b) A question and the corresponding answer, which are based on rote memorization and thus do not foster students' scientific thinking:

\footnotetext{
The boiling point of $\mathrm{Cl}_{2} \mathrm{O}$ is lower than the boiling point of $\mathrm{H}_{2} \mathrm{O}_{2}$. Explain this fact.

The acceptable answer for this question: The boiling point of $\mathrm{Cl}_{2} \mathrm{O}$ is lower than the boiling point of $\mathrm{H}_{2} \mathrm{O}_{2}$ because the hydrogen bonds between the $\mathrm{H}_{2} \mathrm{O}_{2}$ molecules are stronger than the van der Waals interactions between the $\mathrm{Cl}_{2} \mathrm{O}$ molecules.
}

We suggest that students can answer this type of question and score high grades, but the use of the correct terms cannot guarantee that they understand the relevant concepts (such as hydrogen bonds or van der Waals interactions). According to Henderleiter et al. (2001), it appears that students rely on rote memorization to determine which elements could be involved in hydrogen bonding. Although rote memorization of some facts is critical, in many cases it seems that students memorize a list or a pattern but are not able to fully reason through it. Based on these studies and supported by a study conducted previously by Glazer, Ben-Zvi, and Hofstein (1999), we can conclude that in general, common questions cannot serve as a diagnostic tool for evaluating students' understanding. Although it appears that the examination does reveal students' use of alternative conceptions, it does not indicate students' understanding of the underlying concepts because students can provide the correct answer just by using the right terminology. These conclusions are supported by an extensive research effort in science education that demonstrates that success in solving algorithmic exercises does not necessarily indicate understanding of scientific concepts (Lythcott, 1990; Salloum \& Abd-El-Khalick, 2004; Taagepera, Arasasingham, Potter, Soroudi \& Lam, 2002; Teichert \& Stacy, 2002; Vinner, 1997). For example, Lythcott claims that if correct solutions to problems yield high grades but do not guarantee that the relevant chemistry concepts have been understood, then one must seriously question what is being assessed. 
Consequently, the problem is not always the phenomenon of misconceptions; rather, students often answer questions by using the terms used by their teachers but do not actually understand these concepts. Vinner (1997) suggests that whenever students use the right terms in the right context with no conceptual thinking or scientific understanding, they use what he calls pseudoconceptions.

According to previous studies, three main categories of students' difficulties regarding the bonding concept are revealed. These include

- Students confuse intramolecular bonds and intermolecular bonds (Taagepera et al., 2002).

- Students tend to overgeneralize and use rote memorization instead of scientific explanations (Taber \& Watts, 2000).

- Students often use pseudoconceptions; they use the right terms and concepts but do not understand their meaning or their conceptual relevance (Vinner, 1997).

We suggest that the common questions do not examine understanding. Perkins (1998) claims that understanding means being able to carry out a variety of performances, which shows one's understanding of a concept, and at the same time, advances it. He calls such performances understanding performances. Understanding performances have to take students beyond what they already know. Many performances are too routine to be considered understanding performances, such as deciding whether a statement is true or false and solving standard arithmetic exercises. Building from the work of Perkins, it was suggested by Reiser, Krajcik, Moje, and Marx (2003) to use the notion learning performances in order to illustrate the understanding that students should possess as a result of the various tasks performed. They claim that curriculum developers must first determine the key-learning goals, namely, the "big ideas" and the abilities that students should acquire before constructing materials and assessments. They argue that to assess whether students learned the key concepts, developers need to (1) translate the declarative statement of understanding into a set of observable cognitive performances, and (2) be explicit about what kinds of cognitive performances, we would consider as evidence for adequate understanding.

We can conclude that the common questions are not based on specified key-learning goals and thus do not foster the development of understanding aligned with learning performances. According to Birenbaum (1997) and Dori (2003), this system of assessment detracts from teachers' efforts to ensure meaningful learning and the development of students' higher level thinking abilities. In light of this, we recommend abandoning the current pattern of questioning and instead assessing students' argumentation and thinking skills that examine their learning performances. According to Pellegrino, Chudowsky, and Glaser (2001), alignment of assessment, curriculum, and instruction with well-specified key-learning goals is essential for students' meaningful learning.

The Synergic Effect. The previous discussion regarding chemistry textbooks was not meant to blame these books when students do not understand a certain topic or do not think scientifically. As suggested by Kuhn (1970), didactic instruction of currently accepted knowledge is always prone to make knowledge seem more definite and final. The combination of the traditional approach used by curriculum developers worldwide and the demands imposed by the common high-stakes testing generated a growing body of pedagogical content knowledge (PCK) with regard to the bonding concept. This common PCK is overly simplistic, i.e., it includes the use of overgeneralizations and absolute definitions. Therefore, it is not aligned with the up-to-date scientific knowledge and fails in developing 
conceptual understanding. According to Magnusson, Krajcik, and Borko (1999):

PCK is a teacher's understanding of how to help students understand specific subject matter. It includes knowledge of how particular subject matter topics, problems, and issues can be organized, represented, and adapted to the diverse interests and abilities of learners, and then presented for instruction. (p. 96)

The traditional PCK regarding the bonding concept (also termed content-specific pedagogical knowledge by Magnusson et al. (1999)) has been developed during the last decades within the high-school chemistry education community. This content-specific pedagogical knowledge guides many teachers in their classrooms. Decision makers in the chemistryteaching community worldwide often intended to make knowledge seem more definite and final. According to Taber (2005), one of the professional capabilities of the teacher is to find ways to make complex ideas seem accessible, but this must be balanced by the need to present material in a way that is scientifically valid and provides a suitable platform for future learning. In other words, the teacher needs to find the "optimal level of simplification": simplifying sufficiently to suit the learners' present purposes, but not oversimplifying to undermine their future needs. Over the years, this approach became increasingly simplistic and definite in order to facilitate students' learning. Unfortunately, the superficial teaching results in meaningless learning; students often do not understand these concepts, and it is reflected in their misconceptions and in their pseudoconceptions.

Based on these conclusions, it is suggested that an improvement will occur only by a systemic and comprehensive reform efforts in the approach used for teaching the bonding concept. In order to foster students' understanding of this concept, it is essential to propose reconsidering the key-learning goals, revising the content, the pedagogical approach, and the current teaching and assessment methods regarding this concept.

\section{GOALS AND QUESTIONS}

The main goal of this study is to develop an outline for a new teaching approach for high-school chemistry in order to improve understanding of the chemical bonding concept. Thus, we found it necessary to align the teaching of this concept with current scientific and pedagogical knowledge.

\section{Research Questions}

1. What are the key-learning goals and what is suggested as a reform approach to teaching the chemical bonding concept in accordance with senior scientists and with chemistry lead-teachers?

2. Are the new assessment tasks, which were developed based on specified key-learning goals and learning performances (according to the insights raised from the previous question) more diagnostic than the traditional questions on high-stakes examination with regard to students' understanding of the chemical bonding concept?

The Model Used for Aligning the Teaching and the Assessment Approach With Current Scientific Ideas. In this study, we adapted the assessment-driven design model (Reiser et al., 2003) for dealing with the systemic problem that was presented above, namely, the problematic approach of teaching and assessing bonding in the last decades, worldwide. According to Reiser et al. (2003), the central idea of the assessment-driven design process 
is to identify the key-learning goals and to use these "big ideas" to guide all phases of the curriculum and activity design, while constantly assessing whether the tasks are aligned with the "big ideas." This idea is supported by Kesidou and Roseman (2002) who suggest that the instructional design of the curricular materials has to effectively support the attainment of the specified student learning goals. The mere presence of specific content in a curriculum material does not ensure that students will learn that content. For learning to take place, curriculum materials need to focus sound instructional and assessment strategies specifically on the ideas and skills that students are intend to learn and perform.

As we mentioned in the introduction, during the whole process of developing instructional materials, it is important to ensure that the learning goals, the pedagogical approach, as well as the learning performances and the new assessment tasks are aligned in order to foster meaningful learning. Based on the model of Reiser et al. (2003) and on the literature review, we designed this study process, which enabled us to reconstruct a conceptual framework for teaching and assessing the concept of bonding. The structure of the process is described graphically by a schematic outline, as shown in Figure 1.

Based on the finding from our previous study that the examinations' demands amplify students' misconceptions and pseudoconceptions, we began our process with discussions regarding the common questions (the high-stakes testing) that have a central influence on the way this concept is taught (see the right-hand-side gray box in Figure 1). The three hyphenated-line boxes present the problematic factors we intend to treat.

In order to recharacterize the concept of chemical bonding, we had to align the scientific content and the pedagogical approach with current scientific views and knowledge. We have based the new approach on the research participants' views. The participants and the methods we used during this process are detailed in the following section. According to the research participants' views regarding the "big ideas" and their pedagogical insights (see the box on the far left in Figure 1), we could build an outline for an alternative pedagogy. This process included the formulation of specified learning goals and learning

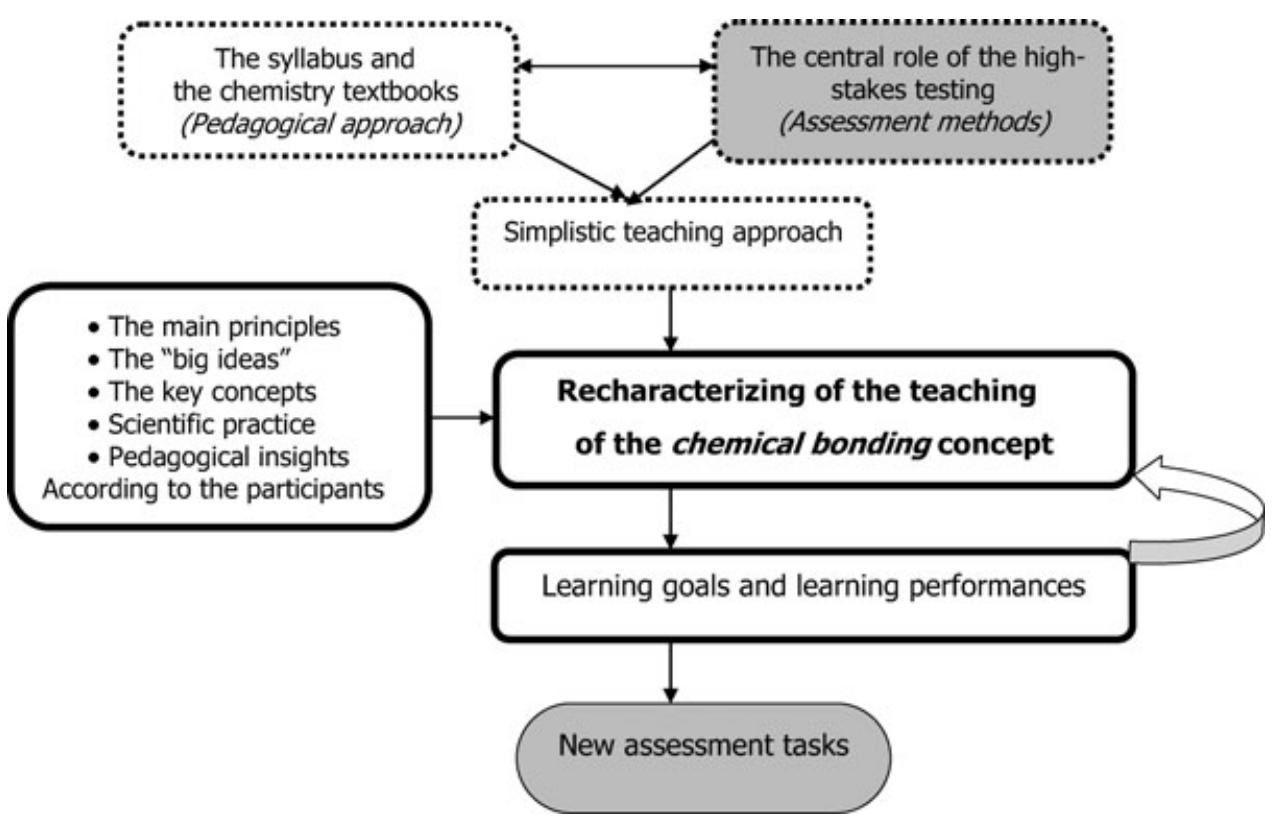

Figure 1. The research model for aligning the teaching approach with current science. 
performances with respect to the scientific practice. Based on these learning performances, several assessment tasks were developed.

\section{METHODOLOGY}

The process, which is described in Figure 1, guided the research plan; more specifically, this process enabled us to answer the research questions and based on these answers to achieve our main goal, namely, to develop a new teaching approach for the bonding concept. We chose the research participants and the activities in order to carry out this process in the most scientific and effective way. We were required to design a collaborative work with several participants: lead-chemistry teachers, researchers in the area of chemistry teaching, chemistry curriculum developers, and senior chemists. We used several methods and activities such as a scientific symposium, a focus group (Fontana \& Frey, 1998; Krueger \& Casey, 2000; Morgan, 1988), and in-depth interviews in order to answer the research questions.

\section{The Research Participants and Their Role in the Study}

We chose the following participants and activities, as shown in Table 1, in order to

- carry out the process described in Figure 1,

- use its outcomes for the development of a new teaching approach for the chemical bonding concept, and

- conduct a preliminary assessment of the new assessment tasks.

\section{Sources and Methods}

As shown in Table 1, we used several activities and tools throughout a triangulation method in order to collect relevant and reliable data. In addition, we used a particular data source based on 14 years of analyses of the ME; the details of all these sources are as follows.

Databases Revealed From the Analyses of the Matriculation Examinations. The ME questions and answers regarding bonding were analyzed each year over a period of 14 years. These analyses serve as a database of students' grades, common misconceptions, alternative conceptions, authentic quotations of students, teachers' views of these questions and answers, as well as teachers' recommendations on how to overcome these misconceptions and more. In the diagnostic study, we reanalyzed it and integrated this database. For more details and several students' citations, see Levy Nahum et al. (2004). Based on this information, we could identify the external misleading factors regarding the teaching and learning of the bonding concept.

As detailed below, during the current study, we used this massive data source as a profound and reliable resource at some stages in the research: in the workshop, in the in-depth interviews with the scientists, as well as in designing the content and the structure of the achievement test.

A Scientific Symposium. A scientific symposium was organized by one of our research participants, a senior chemical physicist from the Weizmann Institute of Science; the symposium included brainstorming and deliberations regarding chemical bonding. Twenty chemistry lead-teachers attended the symposium; they were invited personally by one of the 
TABLE 1

The Research Participants and the Main Data Sources

\begin{tabular}{|c|c|c|}
\hline Participants & The Participants' Role & Data-Sources From the Activities \\
\hline $\begin{array}{l}\text { Senior chemists } \\
\text { and senior } \\
\text { chemistry } \\
\text { educators } \\
(N=10)\end{array}$ & $\begin{array}{l}\text { To provide us with their scientific } \\
\text { perceptions and explanations } \\
\text { regarding the concept of } \\
\text { chemical bonding and their } \\
\text { views regarding the } \\
\text { pedagogical approach for } \\
\text { teaching this concept }\end{array}$ & $\begin{array}{l}\text { Tapes and notes from } 10 \\
\text { in-depth interviews with the } \\
\text { scientists }\end{array}$ \\
\hline $\begin{array}{l}\text { A senior chemical } \\
\text { physicist (from } \\
\text { the } 10 \text { above) }\end{array}$ & $\begin{array}{l}\text { To provide } 20 \text { chemistry } \\
\text { lead-teachers (who are } \\
\text { experts in chemistry teaching) } \\
\text { with a scientific symposium }\end{array}$ & $\begin{array}{l}\text { Tapes and notes from the } \\
\text { symposium }\end{array}$ \\
\hline $\begin{array}{l}\text { Experts in } \\
\text { chemistry } \\
\text { teaching } \\
(N=10) \text {. } \\
\text { These experts } \\
\text { are chemistry } \\
\text { lead-teachers } \\
\text { (10 of the } 20 \\
\text { who attended } \\
\text { the scientific } \\
\text { symposium) }\end{array}$ & $\begin{array}{l}\text { To provide us with the views of } \\
\text { experts in chemistry teaching } \\
\text { regarding } \\
\text { 1. the problematic ME } \\
\text { questions and answers, } \\
\text { 2. the problems regarding the } \\
\text { current pedagogical approach, } \\
\text { and } \\
\text { 3. the scientists' views of } \\
\text { chemical bonding. } \\
\text { Through brainstorming and } \\
\text { focused discussions, we } \\
\text { aimed at formulating the main } \\
\text { learning goals and } \\
\text { constructing a new approach } \\
\text { for teaching the chemical } \\
\text { bonding concept including the } \\
\text { development of new } \\
\text { assessment tasks (based on } \\
\text { set of learning performances) }\end{array}$ & $\begin{array}{l}\text { Tapes and notes from the focus } \\
\text { group that was conducted with } \\
\text { these experts throughout a } \\
\text { workshop during the academic } \\
\text { year } 2005 \text { (six meetings, } \\
4 \text { hours each) }\end{array}$ \\
\hline $\begin{array}{l}\text { 11th-grade } \\
\text { chemistry } \\
\text { students } \\
(N=77)\end{array}$ & $\begin{array}{l}\text { In order to examine new } \\
\text { assessment tasks (which were } \\
\text { developed during the } \\
\text { workshop) compared to the } \\
\text { traditional ME questions, we } \\
\text { administered an achievement } \\
\text { test to } 11 \text { th-grade chemistry } \\
\text { students who studied the } \\
\text { traditional program }\end{array}$ & $\begin{array}{l}\text { Results from the achievement } \\
\text { test }\end{array}$ \\
\hline
\end{tabular}

authors for the purpose of this study. The lecturer (the senior chemical physicist who was involved in this study and prepared his presentation based on several conversations with one of the authors) presented his own views regarding the concept of chemical bonding based on current scientific research studies and advanced knowledge.

In this lecture, entitled "Chemistry—starting from fundamental principles," the leadteachers were exposed to an alternative approach by which this concept may be presented. This approach is mainly based on quantum mechanics and computational science 
techniques; therefore, it cannot be used in high school; however, the main idea, according to this approach, is that all chemical bonds can be explained by the same small number of principles and concepts. This approach encouraged the teachers to reexamine the current teaching approach. During the discussion, the teachers provided their views and cited problematic issues; the whole symposium (the lecture and the discussion that followed it) was recorded, and the protocols were transcribed.

Note that the lecturer was one of the interviewees, who became deeply involved in the process (presented in Figure 1) and acted as a scientific advisor throughout the stages of developing an alternative approach.

Semistructured In-Depth Interviews With Senior Scientists. Eminent chemists from Israel and abroad (including the two Nobel Prize laureates in chemistry Roald Hoffmann (1981) and Aaron Ciechanover (2004)) were interviewed regarding the concept of chemical bonding (three chemical physicists, two organic chemists, two biochemists, and one inorganic chemist). They were asked how they explain chemical bonds, what are the main underlying principles that are needed for teaching the concept of bonding, their views regarding the way bonding is presented in textbooks, and more. During the individual interviews, these chemists expressed a range of acceptable concepts and principles regarding bonding, and their views of the way this concept is presented, assessed, and taught by teachers and lecturers in high school and in college. In addition, British and American senior chemistry educators were interviewed and were asked to refer to and to identify the universal problem underlying the teaching of the bonding concept worldwide based on their rich experience and on the ME analyses in Israel. These interviews were recorded, and the transcripts were analyzed.

A Workshop With Experts in Chemistry Teaching (a Focus Group). In this study, experts in chemistry teaching $(N=10)$ attended a workshop during the academic year 2005, to discuss the traditional approach used for teaching this concept and its discrepancy with the current scientific views. The aim of the experts, along with the researchers, was to develop a reform framework for teaching and learning the chemical bonding concept. These experts ( 10 of the 20 chemistry lead-teachers that attended the symposium, see Table 1 , column 2) were chemistry lead-teachers who are also curriculum developers and/or lecturers of undergraduate chemistry students and/or researchers in science teaching.

At this stage, it is important to elaborate on the rationale for adapting the focus group method. According to Powell and Single (1996), this method is particularly suited for obtaining several perspectives about the same topic. Focus group research involves an organized discussion with a selected group of individuals to gain information about their views and experiences regarding a topic as well as insights into experts' shared understanding of the topic. The recommended number of participants is usually six to ten. Although a focus group is a form of a group interview, Morgan (1997) emphasizes the differences between the two: the group interview involves interviewing a number of people at the same time based mainly on questions and responses between the researchers and the participants; focus groups, however, rely on the interactions and dynamics within the group in relation to topics that are supplied by the researcher. To use the focus group as a forum for change, the moderator (the researcher) must allow the participants to talk to each other, ask questions, and express doubts and opinions (Morgan, 1988).

Accordingly, in this study, a group of 10 experts was selected and assembled by the authors of this paper to discuss and comment based on their personal experience on the way that chemical bonding should be taught. We held six meetings, each of which lasted 
for 4 hours. During the workshop, the following issues were discussed and elaborated by using a focus group method:

- the common questions regarding this concept; more specifically, the problematic content and structure of the high-stakes questions and the "acceptable" answers,

- the scientists' views regarding the concept of chemical bonding and their ideas regarding the learning goals associated with its teaching, and

- the design of new assessment tasks based on decisions regarding the learning goals and the learning performances.

In all the discussions, there was a continuous collaborative exchange of ideas. The useful data produced by the interactions within the group provided the researchers with pedagogical insights that could be used for the development of a new pedagogical approach. In order to enrich the data collected, we used a unique technique during the workshop meetings in which one of the authors, as a focus group moderator, made a reference to parts of previous discussions quotations and asked the participants questions about them. During the meetings, each sentence was recorded and the transcripts were analyzed.

\section{Students' Achievement Test: Assessing Students' Ability to Perform Their Learning.}

During the workshop, the lead-teachers developed a set of learning performances, based on the learning goals. Table 2 presents this set of learning performance. Using these learning performances, we developed new assessment tasks (see the appendix) in order to design an achievement test. The achievement test was validated (validation of content and structure) by a group of experts in chemistry teaching; it included seven open-ended questions: four that are common ME questions, and three others that are new assessment tasks that examined students' learning performances regarding the corresponding topics. By using the achievement test, we wanted to examine the ability of students to answer traditional questions compared to their ability to answer the new tasks. We administered the achievement test to 11 th-grade chemistry students.

\section{Data Analyses}

The data (such as protocols of the symposium, the interviews and the focus group discussions) were gathered and analyzed through qualitative tools and methods. The procedure of

\section{TABLE 2}

\section{A Partial List of Learning Performances Regarding the Bonding Concept}

Explain in your own words the concept of chemical bond

Show a certain bond (hydrogen bond/covalent bond/polar bond) in a given drawing of a model and explain its characteristics

Show the strongest/weakest bond in a given drawing of a model and explain your choice

Give examples of other materials that are appropriate to a given model, property, or phenomenon

Draw an example of another molecule/lattice with chemical bonds similar to a given model

Recognize chemical bonds in different contexts

Recognize the atom or atoms containing the greatest/lowest electron density in a given molecule and justify your answer

Provide a list of characteristics of a certain material regarding a given structure (model) and explain each characteristic 
the analysis included several stages based on Shkedi (2004, 2005); these sequential stages are as follows:

- Segmenting each document (a protocol involving a discussion or interview) into units and categorizing each unit according to its content. Some of the categories emerged from the collected data, such as the main principles, the key concepts, the "big ideas," the assessment methods, and the pedagogical insights.

- Developing more general domains, such as ideas concerning chemical bonding, learning goals, and teaching strategies.

- Mapping all documents according to the chosen domains.

- Looking for the foci: Reorganization of the data according to the chosen domains.

- Proposing assertions based on the accumulated data, which will hopefully contribute to a better understanding of the studied issues.

In analyzing the data, we used several triangulation methods, more specifically, we used different sources and multiple methods in order to reduce the uncertainty of interpreting this study and to minimize the invalidity of our conclusions. This is best done by multiplying independent sources of the same phenomenon. The focus group was the central method we used to collect data regarding lead-teachers' perceptions about the bonding concept, but we also discussed with them the common questions and the views of the scientists. By in-depth interviews, we collected data regarding 10 different senior scientists' views on this concept, and we also discussed with each of them some problematic aspects such as the textbooks, teachers' attitudes, students' difficulties, and the traditional assessment methods. By using the triangulation process, via multiple sources and different modes of evidence, it was possible to build a significant interpretation and to get to some insightful conclusions.

In this paper, several excerpts and quotations from the scientists' and the lead-teachers' transcripts are presented. We suggest that these are valid representations of the total information and data that were collected during this study.

The analyses of the achievement test were done by cross-checking the ME questions with the corresponding assessment tasks based on learning performances (see examples in Table 2). By using this achievement test, we intend to show that the ME questions do not necessarily examine students' understanding, whereas the new tasks perhaps do, and that the new approach may foster students' understanding of the bonding concept.

In this part of the paper, we will refer to several findings and products that led us to develop the new teaching approach.

\section{FINDINGS AND PRODUCTS}

In order to answer the first research question, we focused on the main findings as they emerged from the mapping of the protocols of the scientific symposium, the interviews with the scientists, and the discussions with the lead-teachers during the workshop. We categorized the data regarding the perceptions of the senior scientists and the chemistry lead-teachers concerning the teaching of the bonding concept, according to two main aspects:

1. the main principles and concepts of chemical bonding and

2. pedagogical insights regarding the teaching approach. 


\section{Teaching the Bonding Concept: The Main Principles and Concepts}

Perceptions of Scientists Regarding the Concept of Bonding. From the symposium and the interviews with the scientists, we found that most of the scientists focused on a very limited number of physical principles that they suggested be used in order to explain all chemical bonds. They all started by emphasizing the fact that the concept of bonding is highly complex. For example,

Scientist A: ... I teach Introduction Chemistry ... and I found terrible problems regarding the conceptions of my students and I tried to overcome them but it's not easy... I think that part of the problem is that chemistry moves in very strange ways between very quantitative and very qualitative ideas and it involves a fairly sophisticated substructure....

Most of the scientists raised several ideas regarding the elemental principles and the central concepts that should be used to depict and explain chemical bonding, which are as follows:

- "The quantum mechanics is the accepted quantitative theory that scientists use in order to calculate and get solutions for bonding problems."

- "Coulomb's law should be used as a basic qualitative tool for understanding the bonding concept."

- "All chemical bonds are based on repulsive and attractive electrostatic forces according to the Coulomb's law"."

- Columbic explanatory model is necessary but not sufficient; this statement is constrained by quantum principles such as the uncertainty principle. The Coulomb's law relates to charged particles, whereas in the context of the uncertainty principle the electron can only be described by its duality nature as a wave particle. Therefore, the Coulomb's law cannot provide us with quantitative basis.

- There are repulsive forces between the two nuclei and between the electrons and attractive forces between the electrons and the nuclei. A chemical bond is most stable at the point that the repulsive and attractive forces are equal according to quantum calculations.

- "A chemical bond between two atoms is most stable when the energy of the system is minimal (represented by the energy curve) and this is exactly the equilibrium point."

- "There is a broad range of electrostatic forces and thus of chemical bonds."

- "There is a continuum between the ionic bond and the covalent bond and not a dichotomy."

- "Every two atoms that interact can be characterized by their bond energy and bond length."

- "Electronegativity is a very central concept needed for understanding bonding and it is a measured property of any single atom, ion or molecule."

- "There are no pure ionic bonds; all ionic bonds are partially covalent."

- "The bond between two metallic atoms (such as $\mathrm{Li}_{2}$ ) is basically covalent"; in the context of lattices, scientists view the distinction between " "covalent' and 'metallic' bonding, as reflecting the extent of delocalization of electrons."

Perceptions of Chemistry Lead-Teachers Regarding the Concept of Bonding. During the discussions in the workshop, all the participants expressed the need for a coherent understanding of key concepts and organizing principles regarding all types of chemical bonds in order to provide scientific explanations. The moderator (one of the authors who conducted the focus group) presented the scientists' views regarding the big ideas by referring to their 
quotations from the interviews' protocols. After three meetings, a consensus was attained regarding the following ideas and principles that aligned with the scientists' views:

- Coulomb's law is central for understanding all chemical bonds; thus, we should use it for explaining all types of chemical bonds.

- Regarding every two atoms that approach each other, there are repulsive forces between the two nuclei and between the electrons and attractive forces between the electrons and the nuclei. A chemical bond between two atoms is most stable at the point, where the repulsive and attractive forces are equal. At that point, the bond length and the bond energy are determined.

- It is important to emphasize the common fundamental nature of chemical bonds.

- It is important to emphasize the idea of the continuous scale of bond strength.

\section{Teaching the Bonding Concept: Pedagogical Insights}

Perceptions of Scientists Regarding the Traditional Pedagogy. During the symposium, the lecturer argued that the traditional approach in which this concept is presented today is not only nonscientific but may also generate pedagogical learning impediments. In addition, two of the chemists who teach a general chemistry course indicated their dissatisfaction with the approach used in the chemistry textbooks. They maintain that they have to use several textbooks in order to plan their lessons. For example,

Scientist A: I have not found a perfect way to teach; I have found my own ways and each time I struggle... and another struggle is that I always have to deal with the available textbooks, and I don't like what the textbooks say. ... and there is the tension between what I know is true and the way it's presented ...

During the interviews, the scientists refer to several pedagogical issues. For example,

- Since there is a continuum between the ionic bond and the covalent bond and no dichotomy, it is wrong to present the bonds and the materials in terms of "black and white."

Scientist B: There is a general problem with teaching bonding in high school, which can later be detected in the university... what students are taught all the time is an algorithm and they want a clear-cut answer to every question... a bond that is covalent, a bond that is ionic-from their point of view there is nothing in the middle...

- Teachers use absolute definitions (black/white), whereas chemistry is much more complicated

Scientist B: This attempt to "put things into rigid rubrics"-for chemistry-is a mistake we often make, thinking it will make things easier for our students. With regard to chemistry - this is a big mistake, and the conclusion is that it is unnecessary to define things. In some way, definitions collapse.

Scientist C: (regarding hydrogen bonds)... The problem is with the use of absolute definitions by the teachers... Although it is correct to conclude that when a hydrogen bond involves one of the $\mathrm{N}, \mathrm{O}$, or $\mathrm{F}$ atoms, the bond is stronger; however, with $\mathrm{Cl}$ it will be weaker and its strength may decrease with other atoms, but it is not zero! So they shouldn't deny its existence. 
The heart of the problem in teaching bonding is the wrong presentation used by teachers regarding four structures that can be explained by four bonding types. According to scientist $\mathrm{C}$, the focus regarding the teaching of this concept should be on understanding the fundamental nature of the chemical bond, based on the relevant concepts and principles. In doing so, he suggested using simple models but not too simplistic and avoiding overgeneralizations.

- The explanation regarding the formation of chemical bonds must rely on the principle of minimum energy. Often the presentation of bonding and energy is separated because the unit on energy is introduced only later. Almost all the scientists mentioned that these two ideas must be linked. The concept bond energy is essential for understanding the bonding concept.

- The chemistry lessons should be taught differently-to make students understand and not just memorize.

Scientist B: ... What happens is that chemistry becomes a subject that is learned by rote memorization, and rote in itself, is bad. We have to equip our students with the scientific tools that will assist them in formulating scientific reasoning.... with such tools they can think, get intuition, act, perform...

- We should try to avoid generating pedagogical learning impediments.

Scientist C: Using the "octet rule" as an explanation for the formation of bonds may cause learning impediments... from my point of view, we must avoid from teaching conceptual frameworks that might impede further learning, and that will require in the future a replacement of these frameworks with scientific ones.

The scientists claim that teachers tend to ask questions according to the exams' requirements in order to make things easier for their students and to prepare them for these exams. During the interviews, the scientists refer to several assessment issues. They suggest, for example, the following:

- Not asking questions requiring memorization.

- Formulate questions regarding typical tendencies of chemical properties that can be scientifically explained by the students.

Perceptions of Lead-Chemistry Teachers Regarding the Traditional Pedagogy. There were three main issues regarding the teachers' perceptions:

First, difficulties in accepting the new teaching approach-during the workshop, the teachers expressed their doubts regarding the scientific presentation of this concept:

- It is very difficult to teach the "gray" zone of chemistry. The teacher must first present the facts clearly and must teach the "black and white" zones. The first step of teaching must be dichotomous: teaching the two extremes, first ionic/covalent bonds, and only later breaking them apart and reorganizing students' knowledge.

Teacher 1: If I won't emphasize the obvious then there is no point talking about the non obvious... We must provide students with very clear rules and define ionic bonds, metallic and non-metallic elements and only then present the exceptions ... many students can't step out of the dichotomy! 
Teacher 2: I can certainly say that there are exceptions... but it possible that I did not present a scale because the continuous scale of bonds is not a central concept in the traditional way of teaching in high school...

- We need to simplify things and provide students with generalizations and rules because chemistry must be presented as an exact science.

Teacher 3: If I will tell my students that chemistry is everything without a presentation of classifications and definitions, they may ask me: "why is chemistry considered a 'scientific' area?"

There is no doubt that the workshop's participants wanted to initiate a change in the way this concept is being taught; nevertheless, whenever we discussed (during the meetings) the scientific approach that was designed along the process, they tended to go back to their "old and familiar" pedagogy and knowledge.

Second, accepting that the traditional teaching approach is problematic; seeking for a change. The teachers claimed the following:

- The way in which we simplify these concepts is far from "scientifically based chemistry." Teaching complex issues as if they are clear facts makes it more difficult for students. We have to base the chemical bonds concept on central basic principles.

Teacher 1: We tend to teach things that are far from being obvious and simple, but we represent them as such. This approach leads to students' misconceptions....

Third, criticism toward the traditional assessment methods-regarding the assessment method, all the workshop's participants suggested that

- The way students are assessed on bonding must be altered.

- Some of the common questions are not scientific or relevant enough to ask because the answers to these questions cannot be scientifically explained.

During a discussion concerning one of the questions, teacher 1 stated:

Regarding this question, the student must answer according to a rigid pattern, which in this case not only detracts from students' thinking but is also incorrect.

- The common questions are not diagnostic_- "the answers" only tell you whether the student got the answer right or wrong and not whether they understand why.

During a discussion concerning another question, teacher 4 stated:

The problem is that we don't have the ability to distinguish between students who understand and students who recite slogan... As a result, I can get a correct answer from a student but I have no indication regarding his understanding. . .

\section{Products}

Designing a Set of Learning Goals. As was presented in Figure 1, in conducting this study, we included the formulation of specific learning goals based on the scientists' view, the lead-teachers along with the researchers. The following key-learning goals were formulated and defined: 
- Improving the understanding that chemical bonds cannot be described by a set of rigid definitions or through a dichotomous classification.

- Improving the understanding that all chemical bonds are electrostatic forces (plusminus interactions) according to Coulomb's law.

- Improving the understanding that there is a whole range of chemical bonds, which we can map on a continuous scale according to the strength of electrostatic forces.

- Improving the understanding that there are a small number of principles and key concepts that are central and common for all chemical bonds, such as attractive and repulsive forces, the equilibrium point, bond energy, bond length, and electronegativity.

- Fostering the ability to explain scientifically some chemical phenomena and to realize that qualitative models might explain some phenomena but they do not always work.

- Knowing that the quantum mechanics is the accepted quantitative theory that scientists use in order to calculate and obtain solutions for bonding problems.

Recharacterizing the Teaching of the Bonding Concept. As was presented in Figure 1, based on the perceptions of the scientists and the lead-teachers, while keeping in mind the learning goals, we reached several conclusions and suggestions regarding changes that should be undertaken in the teaching approach. The main suggestions are presented in Table 3.

As was presented in Figure 1, based on the learning goals and on the decisions mentioned in Table 3, we have formulated a set of learning performances (Table 2) with respect to scientific practice. Based on these learning performances, we developed several assessment tasks and designed an achievement test.

\section{Results Regarding Students' Achievement Test}

In order to address the second research question, we examined, using an open-ended achievement test, the ability of students (who study according to the traditional approach) to answer traditional ME questions compared with their ability to respond to the new tasks related to the same items. As mentioned before, the achievement test was developed based on the workshop's activities and its products and was validated. The test included seven open-ended questions: four that are common ME questions (questions 1-4) and three other questions (questions 5-7) that are new tasks that examine students' learning performances regarding the corresponding topics (e.g., see the appendix). Through this examination, we aim to attain the following objectives:

- To support our previous study that shows that students can answer ME-type questions and score $100 \%$ of the grade but the grade cannot guarantee their understanding of the relevant terms. Students often demonstrate relevant declarative knowledge but cannot demonstrate their understanding of this knowledge.

- To show that the new assessment tasks, which were developed based on specified learning goals and learning performances (according to the insights raised during this study), are more diagnostic than the traditional ME questions regarding students' understanding of the chemical bonding concept. Therefore, these tasks may serve as a diagnostic tool by which much deeper levels of understanding can be examined.

We have administered the achievement test to 77 eleventh-grade chemistry students in five classes who studied according to the traditional approach. The analysis of the achievement 


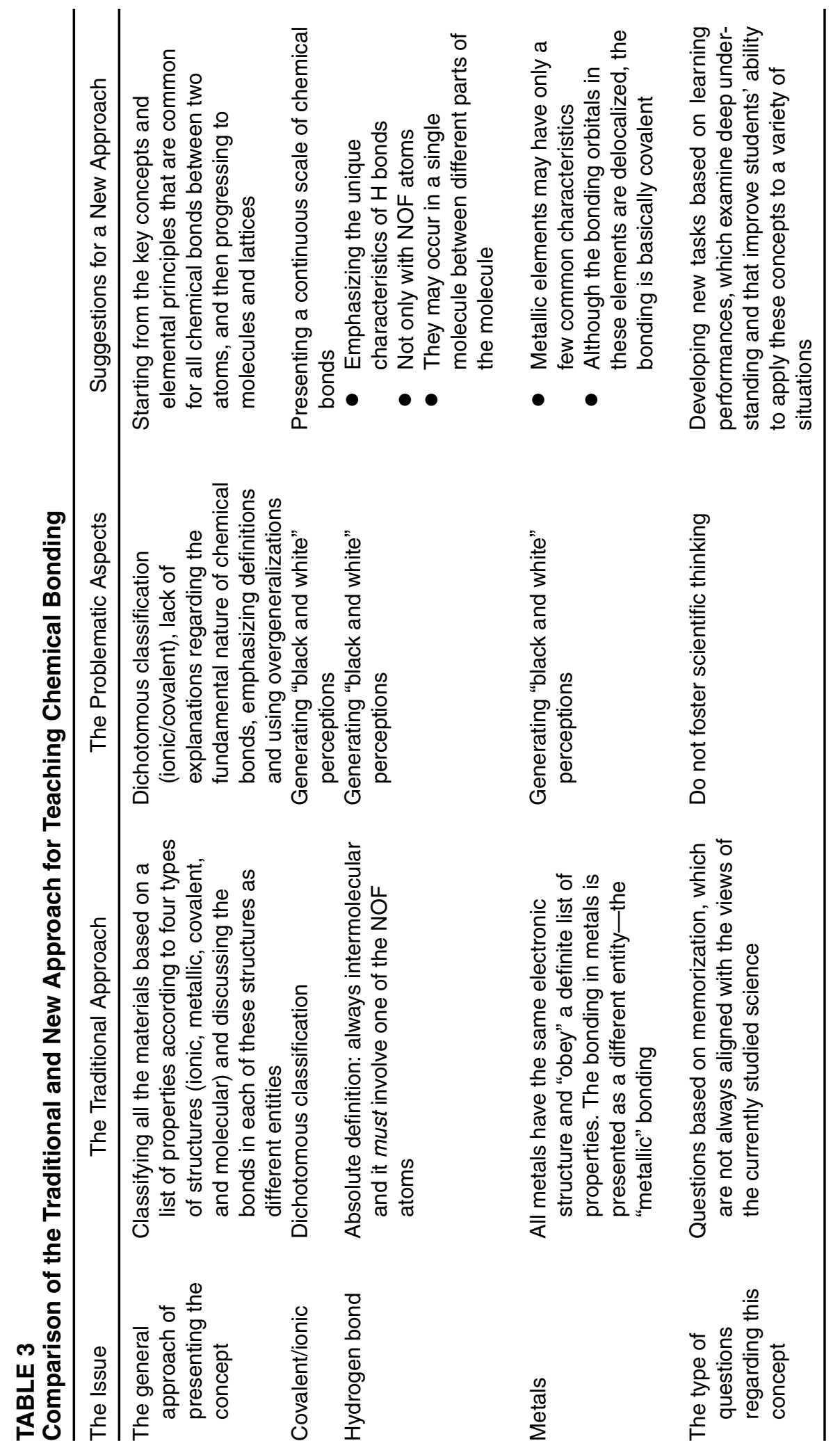

Science Education DOI 10.1002/sce 
test was done by cross-checking the ME questions (1-4) with the corresponding new tasks (5-7) using the McNemar's test. This nonparametric test uses matched pairs of labels (A, B) when only nominal data are available, for example, correct versus incorrect identification of items. It tests whether (A, B) is as likely as (B, A).

According to the validation of the test, we compared

- questions 1 and 2 with question 5 (the item: hydrogen bonds),

- questions 2 and 3 with question 6 (the item: van der Waals interactions), and

- question 4 with question 7 (the item: the giant lattice and properties).

Question 1 (a traditional ME question) will serve as an example:

Which material has a higher boiling point—LiF or HF? Justify your answer.

One of the students, Rami, gave the correct answer, as follows:

The boiling point of HF is lower than the boiling point of LiF because the hydrogen bonds between the HF molecules are weaker than the electrostatic forces between the negative ions and the positive ions in the ionic lattice LiF.

Although this is the correct answer, we cannot conclude from it whether Rami really understand what hydrogen bonds are. We could examine his understanding regarding hydrogen bonds based on his response to question 5, which was a new assessment task. In this task, we asked students to demonstrate their understanding of hydrogen bonds. The task and Rami's answers were as follows:

Task 5(a): In the liquid and the solid states of water there are hydrogen bonds between the molecules. Explain in your own words what hydrogen bonds are.

Rami answered:

Hydrogen bonds are bonds between the $\mathrm{N}-\mathrm{O}-\mathrm{F}$ atoms and the $\mathrm{H}$ atom. They are formed when $\mathrm{H}$ gives its electron to NOF atoms.

Task 5(b): Give an example of another molecular compound in which hydrogen bonds might occur and explain why and how they may be formed.

\section{Rami answered:}

My example is $\mathrm{H}_{2} \mathrm{O}_{2}$-in this molecular compound there are hydrogen bonds between the $\mathrm{O}_{2}$ molecules and the $\mathrm{H}_{2}$ molecules.

In paragraph (c), we presented a model of a few water molecules in the liquid state and asked students to draw by lines a few hydrogen bonds that might occur between the molecules. Rami did not draw any hydrogen bond. Several students that gave the correct answer for the ME question drew lines between two hydrogen atoms, or between two oxygen atoms, or between hydrogen and oxygen in a single water molecule.

The results of the analyses are presented in Table 4 . In the data presented in the two gray columns, it can be seen that $40 \%-70 \%$ of the students succeeded in the ME questions but demonstrated superficial learning in the corresponding new tasks (with regard to parallel 


\section{TABLE 4}

The Results of the Analyses of the Achievement Tests

\begin{tabular}{|c|c|c|c|c|c|}
\hline $\begin{array}{l}\text { Comparison } \\
\text { Between } \\
\text { the Two } \\
\text { Questions }\end{array}$ & $\begin{array}{c}\text { Correct } \\
\text { Answer } \\
\text { for Both } \\
\text { Questions }\end{array}$ & $\begin{array}{c}\text { Wrong } \\
\text { Answer } \\
\text { for Both } \\
\text { Questions }\end{array}$ & $\begin{array}{l}\text { Correct Answer } \\
\text { for the ME } \\
\text { Question and the } \\
\text { Wrong Answer } \\
\text { for the New Task }\end{array}$ & $\begin{array}{c}\text { Wrong Answer } \\
\text { for the ME } \\
\text { Question and the } \\
\text { Correct Answer } \\
\text { for the New Task }\end{array}$ & $\begin{array}{c}\text { McNemar's } \\
\text { Test }\end{array}$ \\
\hline 1 and 5 & $6(7.8 \%)$ & $33(43 \%)$ & 31 (40.2\%) & $6(7.8 \%)$ & $16.9^{*}$ \\
\hline 2 and 5 & 8 (10.4\%) & 37 (48\%) & $29(37.6 \%)$ & $2(2.6 \%)$ & $23.5^{*}$ \\
\hline 2 and 6 & $11(14.2 \%)$ & $12(15.6 \%)$ & 54 (70.1\%) & 0 & $54.0^{*}$ \\
\hline 3 and 6 & $24(31.1 \%)$ & $8(10.4 \%)$ & $41(53.2 \%)$ & $4(5.2 \%)$ & $30.4^{*}$ \\
\hline 4 and 7 & $7(9.1 \%)$ & $20(26 \%)$ & $47(61 \%)$ & 3 (3.9\%) & $38.7^{*}$ \\
\hline
\end{tabular}

*All significant at the $<.0001$ level (based on the McNemar's test).

items), whereas the converse was true for only $0 \%-8 \%$ of the students; namely, they demonstrated some understanding in the new task but did not succeed in the ME-type questions. These findings support our previous study claiming that in many cases students score $80 \%-100 \%$ of the grade in the ME questions although they do not understand the underlying key concepts. Furthermore, based on these findings, we may conclude that the new tasks included components that examine deeper levels of understanding; students are required to perform by using their knowledge and thus these tasks were more diagnostic than the ME-type questions, regarding students' understanding. As pointed out in the introduction, according to Pellegrino et al. (2001), alignment of assessment tasks, with well-specified key-learning goals as well as with learning performances, is essential for students' meaningful learning, and it enables examining a deeper understanding.

\section{DISCUSSION}

The goal of this study was to develop a new pedagogical approach for the teaching of the chemical bond concept. Based on our previous studies and supported by the literature (e.g., Henderleiter et al. 2001; Hurst, 2002; Taber, 1998), we assume that the traditional approach of teaching this concept is problematic. The main aspects of the problem are presented in Table 3. Resolving these problems requires a fundamental change in the way in which the bonding concept is taught. In order to generate a thorough change in the teaching approach, we related to all the problematic aspects and obtained a consensus regarding the organizing principles and the key concepts of this topic based on a partnership between scientists and expert teachers that follows a holistic approach to curriculum. The methods we used enabled us to attain triangulation, and thus we could base our decisions on reliable evidence. According to this study, a reform approach should provide

- scientific frameworks that may prevent pedagogical learning impediments,

- a theoretical basis, which may result in a much deeper understanding of the fundamental nature of chemical bonds and in credible explanations of certain phenomena, and

- a new assessment approach.

Taber and Watts (2000) suggested that we should expect chemistry students to acquire some familiarity with the theoretical frameworks of current science and to develop some level of 
proficiency in applying their knowledge regarding chemical bonds in order to produce valid scientific explanations. Hurst (2002) suggests teaching bonding by presenting all types of chemical bonds based on one central model, since they all result from electrostatic forces; presenting the bonds as different entities, as is often done in textbooks, is misleading.

\section{Changing Direction in Teaching Chemical Bonding}

Based on the findings of this study, an outline was suggested that relies on a "bottomup" approach for teaching the bonding concept. As presented in Table 3, the new approach provides a different theoretical framework; it moves from the submicroscopic level (understanding of the principles that are common to all types of chemical bonds between two atoms in the gas state) and only then progressing toward the microscopic and macroscopic levels (structures and properties of molecules and clusters, which involve much greater complexities). Traditionally, as we presented in the theoretical background section, curriculum developers classify substances according to a "list of properties" into four different groups of lattices (ionic, molecular, covalent, and metallic) and elaborate on and discuss each of these structures based on the chemical bonds that exist between the particles. These types of chemical bonds (ionic, covalent, and metallic bonds) are often discussed as different entities. According to Hurst (2002), this oversimplified presentation misleads chemistry students and may actually cause learning impediments. Conversely, our new approach is based on an understanding of the common principles and concepts suggested for all chemical bonds and then use these ideas to explain the structures and properties of molecules and lattices. This approach is consistent with Hurst (2002) who concluded that the bonding theory and related concepts need to be taught in a uniform manner. The hierarchical structure of this approach is described regarding each stage (1-6) as follows:

1. Single atoms (Coulomb's law, the electron entity, and the concept of orbital).

2. When an atom "meets" another atom to form a chemical bond, it can be explained according to the energy curve (attraction and repulsive of electrostatic forces and the equilibrium point) and can be measured in terms of bond energies and bond lengths at the equilibrium point. The electronic structure and the electronegativity value of each atom are important regarding the type of the bond that might occur between these atoms; at this stage each type of bond is described comprehensively.

3. Two atoms in the gas state may have different bond strengths from very weak to very strong on a continuous scale. As such, two atoms in the gas state could be classified as having weak van der Waals bonds to stronger ionic type bonds as a result of different energy balances. Figure 2 illustrates the range of bond strengths between two atoms.

4. Single polyatomic molecules can be described by characteristics such as the bonds between the atoms in these molecules, structures of molecules and polarity of

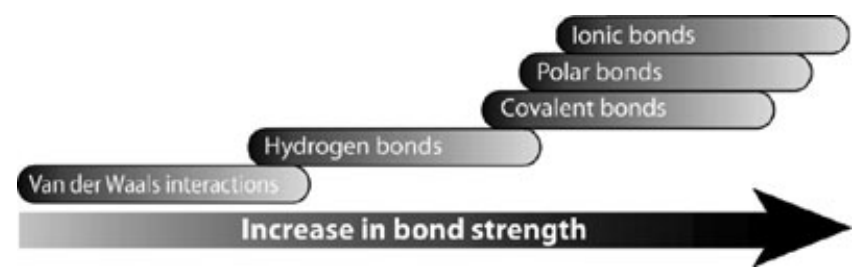

Figure 2. The continuous scale of bond strengths. 
molecules, using the ideas presented in stages $1-3$. At this stage, we apply multiple visual models of molecules accompanied with discussion regarding the aspects each model represents and its limitations.

5. Materials: referring to the way particles (atoms or molecules) aggregate to form a variety of structures. Using the underlying ideas (stages 1-3), we discuss two main groups of materials: molecular and giant lattice.

6. Properties and phenomena of materials with respect to aspects of bonding and structure.

According to this approach, we suggest focusing on the bonds that might be formed between two atoms. On the one hand, we present all chemical bonds (including hydrogen bonds and van der Waals bonds) using the model of interactions between two atoms in the gas state; on the other hand, we emphasize the importance of the ability of students to distinguish between different bonds by their lengths, energies, and other important characteristics such as directionality. Thus, although all these bonds can be presented on a continuous scale of bond strength, students should acquire chemical qualitative understanding regarding the strength of these bonds and their characteristics. For example, students should understand the unique nature of the hydrogen bond and recognize the situations in which it might occur. More specifically, if we discuss the hydrogen bonds between water molecules in the liquid state and the polar covalent bonds between hydrogen and oxygen in a single molecule of water, students should be able to explain the following: (1) The common principles and concepts regarding the hydrogen bond and the polar covalent bond; i.e., both bonds are directional and can be explained by the equilibrium point at which the repulsive and attractive forces are equal and (2) the hydrogen bond between an oxygen atom on one water molecule and the hydrogen atom on an adjacent water molecule is much longer and as a result is much weaker (based on Coulomb's law) than the polar covalent bond between oxygen and hydrogen in a single water molecule. These different bond strengths result from different energy balances. Consequently, the energies required for breaking each bond are largely different and this is reflected in the properties of water.

Our approach is supported by Taagepera et al. (2002) who claim that effective comprehension and thinking require a coherent understanding of the organizing principles. By using a coherent conceptual model for all bonds, we seek to improve students' ability to apply their knowledge of chemical bonds in a variety of contexts aligned with the learning performances. All stages of this research process served as the rationale underlying the researchers' decisions both scientifically and pedagogically regarding the design of the new approach. We suggest that the new approach may foster students and teachers to acquire a much deeper understanding of the underling key concepts and may solve part of the problem that we addressed. Based on the suggested outline, we developed an experimental curriculum.

To sum-up, we hope that the process that we have described here may serve as a useful model for researchers and curriculum developers for aligning the traditional teaching approach with current scientific and pedagogical knowledge in other topics in chemistry as well as in other areas in science.

\section{APPENDIX}

Example of an assessment task

1. The bromine element forms diatomic molecules; one molecule can be represented by the ${ }^{B} B$ Br following model: 
a. Draw models of a few bromine molecules in their three states, in each of these schematic beakers.

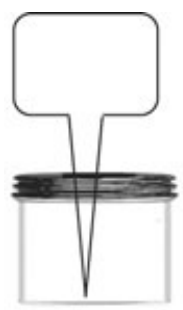

Solid bromine

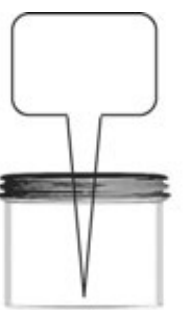

Liquid bromine

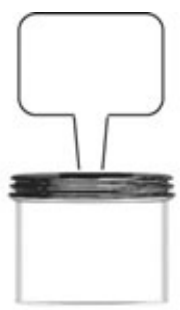

Gas bromine

b. The bromine molecules in the liquid and the solid states are held together by van der Waals interactions. Explain these interactions in your own words.

c. Every two bromine atoms in a given molecule are bonded covalently. Explain the differences between the covalent bond in each molecule and the interactions between the molecules.

d. Give an example of another material with similar intermolecular interactions.

\section{REFERENCES}

Ashkenazi, G., \& Kosloff, R. (2006). The uncertainty principle and covalent bonding. Chemical Educator, 11, 66-76.

Atzmon, A. (1991). Natural science curriculum as designer of the image of science using rhetorical patterns within the socio-political system. Unpublished doctoral dissertation, Hebrew University, Jerusalem (in Hebrew).

Ben-Zvi, R., Eylon, B., \& Silberstein, J. (1986). Is an atom of copper malleable? Journal of Chemical Education, 63, 64-66.

Birenbaum, M. (1997). Alternatives in assessment. Tel-Aviv: Ramot.

Bodner, G., \& Domin, D. (1998). Mental models: The role of representations in problem solving in chemistry. Paper presented at International Council for Association in Science Education, Summer Symposium, Proceedings.

Dori, Y. J. (2003). From nationwide standardized testing to school-based alternative embedded assessment in Israel: Students' performance in the matriculation 2000 project. Journal of Research in Science Teaching, 40, 34-52.

Fensham, P. (1975). Concept formation. In D. J. Daniels (Ed.), New movements in the study and teaching of chemistry (pp. 199-217). London: Temple Smith.

Fontana, A., \& Frey, J. (1998). Interviewing: The art of science. In N. Denzin \& Y. Lincoln (Eds.), Collecting and interpreting qualitative materials (pp. 47-78). Thousand Oaks, CA: Sage.

Gabel, D. (1996, July). The complexity of chemistry: Research for teaching in the 21st century. Paper presented at the 14th International Conference on Chemical Education, Brisbane, Australia.

Gillespie, R. (1997). The great ideas of chemistry. Journal of Chemical Education, 74, 862-864.

Glazer, N., Ben-Zvi, R., \& Hofstein, A. (1999, March). The gap between factual knowledge and conceptual understanding in learning the concept "chemical bonding." Paper presented at the annual meeting of the National Association for Research in Science Teaching, Boston, MA.

Griffiths, A., \& Preston, K. (1992). Grade-12 students' misconceptions relating to fundamental characteristics of atoms and molecules. Journal of Research in Science Teaching, 29, 611-628.

Harrison, A. G., \& Treagust, D. F. (2000). Learning about atoms, molecules, and chemical bonds: A case study of multiple-model use in grade 11 chemistry. Science Education, 84, 352-381.

Henderleiter, J., Smart, R., Anderson, J., \& Elian, O. (2001). How do organic chemistry students understand and apply hydrogen bonding? Journal of Chemical Education, 78(8), 1126-1130.

Herron, J. D. (1996). The chemistry classroom: Formulas for successful teaching. Washington, DC: American Chemical Society.

Hurst, O. (2002). How we teach molecular structure to freshmen. Journal of Chemical Education, 79(6), 763-764.

Johnstone, A. H. (1991). Why is science difficult to learn? Things are seldom what they seem. Journal of Computer Assisted Learning, 7, 75-83. 
Justi, R., \& Gilbert, J. (2002). Models and modeling in chemical education. In J. K. Gilbert, O. D. Jong, R. Justy, D. F., Treagust, \& J. H. Van Driel (Eds.), Chemical education: Towards research-based practice (pp. 47-68). Dordrecht: Kluwer.

Kesidou, S., \& Roseman, J. E. (2002). How well do middle school science programs measure up? Findings from project 2061's curriculum review. Journal of Research in Science Teaching, 39(6), 522-549.

Krueger, R., \& Casey, M. A. (2000). Focus group. London: Sage.

Kuhn, T. (1970). The structure of scientific revolutions. Chicago: University of Chicago Press.

Levy Nahum, T., Hofstein, A., Mamlok-Naaman, R., \& Bar-Dov, Z. (2004). Can final examinations amplify students' misconceptions in chemistry? Chemistry Education: Research and Practice in Europe, 5(3), 301325 .

Lythcott, J. (1990). Problem solving and requisite knowledge of chemistry. Journal of Chemical Education, 67(3), $248-252$.

Magnusson, S., Krajcik, J., \& Borko, H. (1999). Nature, sources, and development of pedagogical content knowledge for science teaching. In J. Gess-Newsome \& N. G. Lederman (Eds.), Pedagogical content knowledge and science education (pp. 95-132). Dordrecht: Kluwer.

Morgan, D. L. (1988). Focus group as qualitative research. Beverley Hills, CA: Sage.

Morgan D. L. (1997). Focus group as qualitative research (2nd ed.). London: Sage.

Pellegrino, J. W., Chudowsky, N., \& Glaser, R. (Eds.). (2001). Knowing what students know: The science and design of educational assessment. Washington, DC: National Academy Press.

Perkins, D. (1998). What is understanding? In M. S. Wiske (Ed.), Teaching for understanding: Linking research with practice. San Francisco, CA: Jossey-Bass.

Peterson, R. F., \& Treagust, D. F. (1989). Grade-12 students' misconceptions of covalent bonding and structure, Journal of Chemical Education, 66, 459-460.

Powell, R. A., \& Single, H. M. (1996). Focus groups. International Journal of Quality in Health Care, 8(5), 499-504.

Reiser, B., Krajcik, J., Moje, E., \& Marx, R. (2003). Design strategies for developing science instructional materials. Paper presented at the Annual Meeting of the National Association of Research in Science Teaching, Philadelphia, PA.

Robinson, W. (2003). Chemistry problem-solving: Symbol, macro, micro, and process aspects. Journal of Chemical Education, 80, 978-982.

Salloum, S., \& Abd-El-Khalick, F. (2004). Relationships between selective cognitive variables and students' ability to solve chemistry problems. International Journal of Science Education, 26(1), 63-84.

Shkedi, A. (2004). Second-order theoretical analysis: A method for constructing theoretical explanation. International Journal of Qualitative Studies in Education, 17(5), 627-646.

Shkedi, A. (2005). Multiple case narrative: A qualitative approach to the study of multiple populations. Amsterdam: John Benjamins.

Taagepera, M., Arasasingham, R., Potter, F., Soroudi, A., \& Lam, G. (2002). Following the development of the bonding concept using knowledge space theory. Journal of Chemical Education, 79(6), 756-762.

Taber, K. S. (1998). An alternative conceptual framework from chemistry education. International Journal of Science Education, 20, 597-608.

Taber, K. S. (2001). The mismatch between assumed prior knowledge and the learners' conceptions: A typology of learning impediments. Educational Studies, 27(2), 159-171.

Taber, K. S. (2002). Chemical misconceptions-Prevention, diagnosis and cure, Vol. 1: Theoretical background. London: Royal Society of Chemistry.

Taber, K. S. (2005). Learning quanta: Barriers to stimulating transitions in student understanding of orbital ideas. Science Education, 89, 94-116.

Taber, K. S., \& Coll, R. (2002). Bonding. In J. K. Gilbert, O. D. Jong, R. Justy, D. F. Treagust, \& J. H. Van Driel (Eds.), Chemical education: Towards research-based practice (pp. 213-234). Dordrecht: Kluwer.

Taber, K. S., \& Watts, M. (2000). Learners' explanations for chemical phenomena. Chemistry Education: Research and Practice in Europe, 1(3), 329-353.

Teichert, M., \& Stacy, A. (2002). Promoting understanding of chemical bonding and spontaneity through student explanation and integration of ideas, Journal of Research in Science Teaching, 39(6), 464-496.

Tsaparlis, G. (1997). Atomic and molecular structure in chemical education. Journal of Chemical Education, 74, 922-925.

Vinner, S. (1997). The pseudo-conceptual and the pseudo-analytical thought processes in mathematics learning. Educational Studies in Mathematics, 34, 97-129.

Wiggins, G., \& McTighe, J. (1998). Understanding by design. Upper Saddle River, NJ: Merrill Prentice Hall.

Wilson, M. R., \& Bertenthal, M. W. (Eds.). (2006). Committee on test design for K-12 science achievement. Washington, DC: National Academies Press. 